\title{
Long-term outcome with intravenous iloprost in pulmonary arterial hypertension
}

\author{
M.M. Hoeper*, H. Gall\#, H.J. Seyfarth", M. Halank+, H.A. Ghofrani”, J. Winkler", \\ H. Golpon*, K.M. Olsson*, N. Nickel*, C. Opitz ${ }^{\S}$ and R. Ewert ${ }^{f}$
}

ABSTRACT: There is limited data on the long-term efficacy of intravenous iloprost in patients with pulmonary arterial hypertension (PAH).

This retrospective multicentre analysis evaluated the clinical course of patients with PAH treated with i.v. iloprost, in most cases after having received inhaled iloprost as first-line therapy.

Between 1997 and 2001, 79 PAH patients were treated with i.v. iloprost and followed until 2007. These patients had advanced and progressive disease as indicated by a mean pulmonary vascular resistance of $1,533 \mathrm{dyn} \cdot \mathrm{s} \cdot \mathrm{cm}^{-5}$ at the time of diagnosis and of $1,858 \mathrm{dyn} \cdot \mathrm{s} \cdot \mathrm{cm}^{-5}$ at the onset of $i . v$. iloprost therapy. Introduction of $i . v$. iloprost therapy resulted in initial haemodynamic and clinical improvement. At the end of the observation period, however, $50(61 \%)$ patients had died and $21(26 \%)$ required lung transplantation. Transplantation-free survival rates at 1, 3, and 5 yrs were $86 \%, 59 \%$ and $45 \%$, respectively, after the diagnosis of PAH, and $54 \%, 31 \%$ and $15 \%$, respectively, after the introduction of $i . v$. iloprost therapy. Predictors of an adverse outcome at baseline were a low 6-min walk distance and a low mixed venous oxygen saturation.

In conclusion, despite initial haemodynamic and clinical improvement, overall long-term survival with i.v. iloprost therapy was limited.

KEYWORDS: Hypertension, iloprost, prognosis, prostanoids, pulmonary

$\mathbf{T}$ he treatment of severe pulmonary arterial hypertension $(\mathrm{PAH})$ has changed substantially during the past couple of years. In the early 1990s, intravenous epoprostenol, a prostacyclin analogue, was the only drug with proven efficacy in this condition and thus, epoprostenol was used as first-line treatment in the vast majority of $\mathrm{PAH}$ patients [1-3]. Since the mid-1990s, nonparenteral treatments have been developed and approved for $\mathrm{PAH}$, including endothelin receptor antagonists [4], phosphodiesterase (PDE) 5 inhibitors [5] and prostanoid analogues [6]. These drugs are now widely used in $\mathrm{PAH}$, especially in patients presenting in functional classes II and III, while i.v. epoprostenol became more of a rescue medication for patients presenting in functional class IV or those deteriorating while receiving less invasive medical therapies $[7,8]$.

In Germany, epoprostenol has never been approved for $\mathrm{PAH}$ and for historical reasons, iloprost has become the standard prostanoid for inhaled and i.v. use in this country, although this drug has also not been approved for i.v. administration. i.v. iloprost is also widely used to treat

For editorial comments see page 7.
PAH in some other European countries, including the UK and Spain. Compared with epoprostenol, iloprost has the potential advantages of being more stable in solution and having a longer plasma half-life $[9,10]$, which makes its use more convenient and possibly safer. However, it has never been formally studied whether iloprost is as efficacious as epoprostenol in PAH and few longterm data with i.v. iloprost have been published $[11,12]$. To the best of our knowledge, only two studies have directly compared i.v. epoprostenol and i.v. iloprost $[13,14]$. Both studies suggested that epoprostenol and iloprost are of comparable efficacy, but these data must be considered preliminary as the two studies were not randomised and were limited in size and duration.

As more data on the efficacy of i.v. iloprost are needed, we analysed the long-term outcome of patients treated with i.v. iloprost in five German centres that specialise in the treatment of PAH.

\section{METHODS}

Data were retrospectively analysed from all PAH patients in whom i.v. iloprost treatment was instituted in the participating centres (university hospitals of Berlin, Dresden, Giessen, Hanover and Leipzig, all Germany) between January 1,
AFFILIATIONS

*Dept of Respiratory Medicine,

Hanover Medical School, Hanover

"Dept of Respiratory Medicine,

University of Giessen Lung Center, Giessen,

"Dept of Respiratory Medicine,

University of Leipzig, Leipzig,

${ }^{+}$Dept of Internal Medicine I, CarlGustav-Carus University Dresden, Dresden,

${ }^{\S}$ Dept of Cardiology, DRK Kliniken Berlin Köpenick, Berlin, and

${ }^{f}$ Dept of Cardiology and Respiratory Medicine, University of Greifswald,

Greifswald, Germany.

CORRESPONDENCE

M.M. Hoeper

Hanover Medical School

Dept of Respiratory Medicine

Carl-Neuberg-Str. 1

30625 Hannover

Germany

E-mail: hoeper.marius@mh-

hannover.de

Received:

Nov 192008

Accepted after revision:

Feb 052009

First published online:

Feb 272009

European Respiratory Journal

Print ISSN 0903-1936

Online ISSN 1399-3003 
1997 and December 31, 2001, i.e. prior to the introduction of endothelin receptor antagonists and PDE5 inhibitors. Followup ended on December 31, 2007 so that the outcome for all patients could be determined for a minimum period of 6 yrs. Inclusion criteria were a diagnosis of $\mathrm{PAH}$ and the introduction of i.v. iloprost treatment at any time during the course of the disease. Patients with other forms of pulmonary hypertension were excluded. This analysis was approved by the institutional review boards of the participating centres. Informed consent was waived according to German regulations for noninterventional, retrospective analyses.

The patients were treated according to the local standards of the enrollment period, which included inhaled iloprost and oral anticoagulants as well as oxygen and diuretics based on individual needs. Inhaled iloprost was administered at dosages 30-45 $\mu \mathrm{g} \cdot \mathrm{day}^{-1}$, divided into 6-9 inhalations. There were no predefined criteria for the introduction of i.v. iloprost therapy. All patients were admitted to the hospital for the initiation of treatment. Iloprost was diluted in normal saline to a total volume of $100 \mathrm{~mL}$ and administered intravenously with a portable pump (CADD-1; Deltec, St Paul, MN, USA) via a port catheter or a Hickman catheter. The medications were prepared under sterile conditions by specialised pharmacists equipped with laminar airflow hoods. Cassettes were changed by the patients every $48 \mathrm{~h}$. Dosing was left to the discretion of the physician in charge and was guided by drug efficacy and sideeffects. Some centres used haemodynamic guidance for the initiation of therapy; in these cases, haemodynamic variables immediately prior to i.v. iloprost treatment and at the end of the initial up-titration period were recorded. There were no prespecified schedules for follow-up right-heart catheterisations.

\section{Statistical analysis}

Statistical analyses were performed with Microsoft Excel 2007 and SPSS 16.0 (SPSS Inc., Chicago, IL, USA). Data are presented as mean \pm SD or median ( $95 \%$ confidence interval), as appropriate. Kaplan-Meier plots were used to illustrate overall survival and transplantation-free survival, respectively, and statistical assessments were performed by the log-rank test. Patients undergoing transplantation were censored at that time for the analysis of overall survival. Chi-squared analysis was used to compare the observed survival rates at 1,2 , and 3 yrs with the expected survival rates. Expected survival (idiopathic PAH (IPAH) only) was calculated according to the National Institutes of Health (NIH; Bethesda, MD, USA) equation [15], with the probability of survival at time $t$ being:

$$
p(t)=H(t)^{A(x, y, z)}
$$

where $H(t)=\left(0.88-0.14 t+0.01 t^{2}\right), A(x, y, z)=\exp (0.007325 x+0.0526 y-$ $0.3235 \mathrm{z}), \mathrm{x}$ is mean pulmonary arterial pressure, $\mathrm{y}$ is mean right atrial pressure and $\mathrm{z}$ is cardiac index. The probabilities of survival at 1,2 , and 3 yrs were calculated as $\mathrm{p}(1)=0.75^{\mathrm{A}}, \mathrm{p}(2)=0.65^{\mathrm{A}}$, and $\mathrm{p}(3)=0.55^{\mathrm{A}}$, respectively. Univariate and multivariate Cox analyses according to the stepwise forward likelihood ratio method were carried out to identify risk factors of an adverse outcome (death or lung transplantation) using age, functional class, 6-min walk distance and haemodynamics at the time of diagnosis and at the onset of i.v. iloprost therapy. Differences between haemodynamic parameters at baseline, at the time of initiation of iloprost therapy, after the initial up-titration and during follow-up were assessed with one-way ANOVA. Multiple comparisons were made when the F-test was statistically significant. A paired t-test was used to compare the 6-min walk distances prior to i.v. iloprost therapy and 3 months later. p-values $<0.05$ were considered statistically significant.

\section{RESULTS}

Between January 1, 1997 and December 31, 2001 a total of 480 patients with $\mathrm{PAH}$ were treated in the participating centres. Out of these, $79(18 \%)$ received i.v. iloprost and were eligible for this analysis. The baseline characteristics of the study patients are shown in table 1 . The clinical courses of some of these patients have been presented in earlier publications [11, 12]. None of the patients in the present series had a positive response to acute vasodilator challenge. Initial treatment included anticoagulation, diuretics and oxygen as needed. Inhaled iloprost was used as first-line therapy in the vast majority $(n=75 ; 95 \%)$ of the patients, while only four $(5 \%)$ patients were treated immediately with i.v. iloprost. The interval between the initial diagnosis of PAH and the initiation of i.v. therapy ranged 0-69 months (median 12 months).

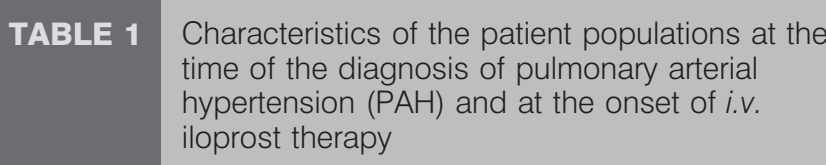

Population under study

\begin{tabular}{|c|c|c|}
\hline & \multicolumn{2}{|c|}{ Population under study } \\
\hline & Time of diagnosis & Onset of i.v. iloprost \\
\hline Subjects n & \multicolumn{2}{|c|}{79} \\
\hline Female/Male & \multicolumn{2}{|c|}{$59 / 20(75 / 25)$} \\
\hline Age yrs & $47 \pm 13$ & $48 \pm 14$ \\
\hline \multicolumn{3}{|l|}{ Diagnosis } \\
\hline $\mathrm{IPAH}$ & \multicolumn{2}{|c|}{$62(78)$} \\
\hline PAH-CTD & \multicolumn{2}{|c|}{$10(13)$} \\
\hline $\mathrm{PAH}-\mathrm{CHD}$ & \multicolumn{2}{|c|}{$2(3)$} \\
\hline $\mathrm{PoPH}$ & \multicolumn{2}{|c|}{$5(6)$} \\
\hline Functional NYHA class III/IV & $61 / 18(77 / 23)$ & $24 / 49(33 / 67)^{\#}$ \\
\hline 6-min walk distance $\mathrm{m}$ & $287 \pm 112$ & $228 \pm 114^{\circ}$ \\
\hline \multicolumn{3}{|l|}{ Haemodynamics } \\
\hline Pra $\mathrm{mmHg}$ & $10 \pm 6$ & $13 \pm 6$ \\
\hline $\bar{P}$ pa $\mathrm{mmHg}$ & $57 \pm 12$ & $61 \pm 15$ \\
\hline Ppcw mmHg & $8 \pm 6$ & $8 \pm 3$ \\
\hline $\mathrm{CO} L \cdot \min ^{-1}$ & $3.0 \pm 1.0$ & $2.7 \pm 0.8$ \\
\hline Cardiac index $\mathrm{L} \cdot \mathrm{min}^{-1} \cdot \mathrm{m}^{-2}$ & $1.7 \pm 0.6$ & $1.5 \pm 0.4$ \\
\hline PVR dyn $\cdot s \cdot \mathrm{cm}^{-5}$ & $1,533 \pm 624$ & $1,858 \pm 856$ \\
\hline $\mathrm{Sv}, \mathrm{O}_{2} \%$ & $54 \pm 11$ & $47 \pm 10$ \\
\hline \multicolumn{3}{|c|}{ 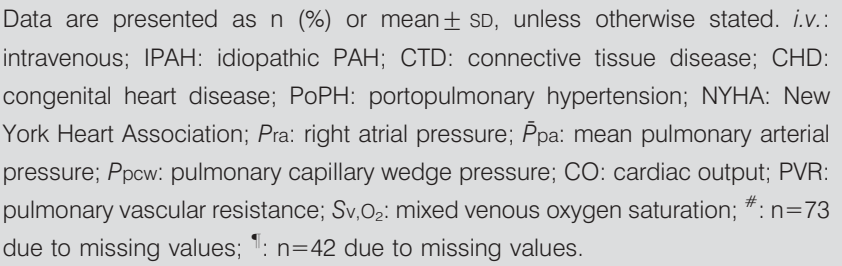 } \\
\hline
\end{tabular}


During the observation period, 50 (61\%) patients died and 21 $(26 \%)$ additional patients underwent lung or heart-lung transplantation, resulting in an overall transplantation-free survival of $10 \%$. The median survival from the time of diagnosis was 33 months (range 0-108 months). The median survival from the initiation of i.v. iloprost was 12 months (range 0-108 months).

\section{Survival from the initial diagnosis}

The probabilities of overall survival, i.e. when patients were censored at the time of lung transplantation, from the time of diagnosis after 1, 2, 3, 4, 5 and 6 yrs were $86 \%, 73 \%, 59 \%, 46 \%$, $40 \%$ and $36 \%$, respectively (data not shown). The probabilities of transplantation-free survival from the time of diagnosis after $1,2,3,4,5$ and 6 yrs were $82 \%, 65 \%, 54 \%, 33 \%, 26 \%$ and $23 \%$, respectively (fig. 1).

In the subpopulation of IPAH patients $(n=62)$, transplantationfree survival rates from the time of diagnosis for the IPAH population under study after 1, 2, 3, 4, 5 and 6 yrs were $86 \%$, $65 \%, 44 \%, 32 \%, 26 \%$ and $23 \%$ respectively (data not shown).

Predictors of death according to univariate Cox regression analysis were a low 6-min walk distance, a low cardiac index, a high pulmonary vascular resistance and a low mixed venous oxygen saturation at the time of the diagnosis. In the stepwise multivariate analysis, the only factors that remained statistically significant were a low 6-min walk distance and a low mixed venous oxygen saturation (table 2).

\section{Survival from the initiation of i.v. iloprost therapy}

Figure 2 shows the outcome for the entire patient population after the introduction of i.v. iloprost therapy. The probabilities of transplantation-free survival from the initiation of i.v. iloprost therapy after 1, 2, 3, 4, 5 and 6 yrs were $54 \%, 35 \%$, $31 \%, 24 \%, 15 \%$ and $13 \%$, respectively.

The results were similar for the IPAH subpopulation, with transplantation-free survival rates 1, 2, 3, 4, 5 and 6 yrs after the start of i.v. iloprost of $57 \%, 37 \%, 32 \%, 26 \%, 18 \%$ and $15 \%$, respectively (data not shown). The expected survival rates of

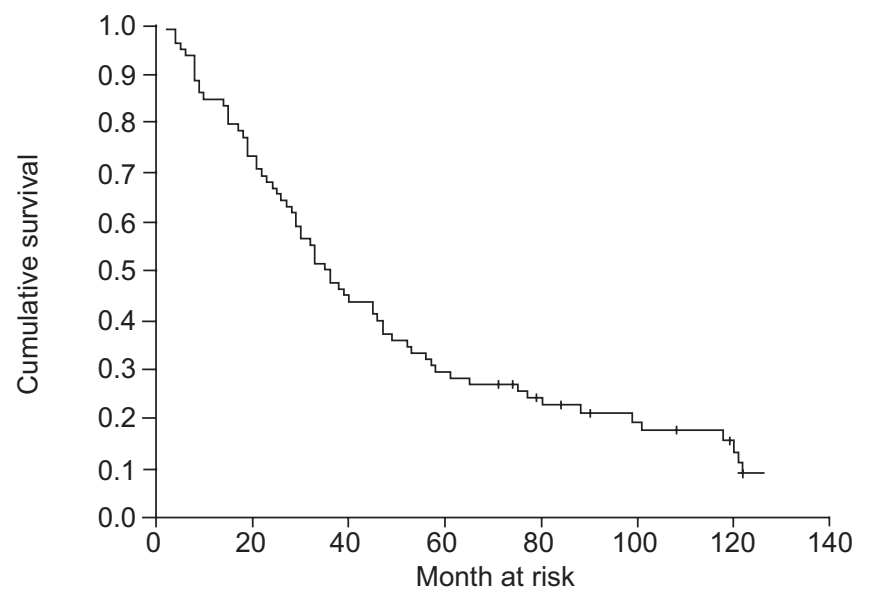

FIGURE 1. Transplantation-free survival from the time of diagnosis of patients with pulmonary arterial hypertension treated with a sequential approach of inhaled and $i$.v. iloprost $(n=79)$. Numbers at risk were $n=64, n=51, n=37, n=26, n=20$ and $\mathrm{n}=17$ after $1,2,3,4,5$ and 6 yrs, respectively. |: censored. these patients after 1, 2 and 3 yrs, calculated with the NIH registry equation based on the haemodynamic parameters obtained immediately before the onset of i.v. iloprost therapy, were $58 \%, 44 \%$ and $34 \%$, respectively, i.e. almost identical to the observed survival (nonsignificant differences at all three time-points; data not shown).

A modified hazard analysis with parameters obtained at the time of the initiation of i.v. iloprost therapy (table 3) revealed similar results to the hazard analysis using parameters at the time of the diagnosis with the difference that New York Heart Association class was now significantly associated with the outcome in the univariate, although not in the multivariate, analysis, whereas the 6-min walk distance was no longer a significant predictor of outcome (statistical power limited by low numbers because of missing values).

\section{Iloprost dose, haemodynamic effects and exercise tolerance}

The dose of iloprost at the time of discharge was $1.8 \pm 0.8 \mathrm{ng} \cdot \mathrm{kg}^{-1} \cdot \mathrm{min}^{-1}$. As shown in table 4 , there was a significant immediate haemodynamic improvement associated with the start of i.v. iloprost with a drop in the pulmonary vascular resistance from $1,965 \pm 871$ to $1,474 \pm 606 \mathrm{dyn} \cdot \mathrm{s} \cdot \mathrm{cm}^{-5}$ $(-25 \%)$. Follow-up right heart catheter examinations 215 months (median 6 months) after initiation of i.v. iloprost were available for 37 patients. At that time, the iloprost dose was $2.6 \pm 1.2 \mathrm{ng} \cdot \mathrm{kg}^{-1} \cdot \mathrm{min}^{-1}$. The pulmonary vascular resistance was now $1,594 \pm 651 \mathrm{dyn} \cdot \mathrm{s} \cdot \mathrm{cm}^{-5}$, i.e. slightly higher than immediately after the introduction of $i . v$. iloprost therapy but still substantially lower than before (-19\% from baseline).

Functional class was assessed in 72 patients directly before the start of i.v. iloprost and 3 months later. It improved by at least one class in 27 patients (38\%), was unchanged in 44 patients $(61 \%)$, and worsened in one patient $(1 \%)$. At the same time, measurements of 6-min walk distance were available from 29 patients and showed an increase from $228 \pm 114$ to $310 \pm 74 \mathrm{~m}$ $(p=0.002)$.

\section{Adverse events related to therapy}

A total of eight episodes of catheter-related bloodstream infections were reported in six patients and two of these episodes were directly related to death. However, owing to the retrospective nature of this study, under-reporting cannot be ruled out. Other side-effects included headache, jaw pain, leg pain, nausea and diarrhoea, but these side-effects were manageable with adaptation of the iloprost dose and did not lead to treatment withdrawals.

\section{DISCUSSION}

The present retrospective analysis showed that patients with advanced PAH have a high rate of treatment failure when treated sequentially with inhaled and i.v. iloprost. In this patient population, the transplantation-free survival rates from the time of diagnosis after 1, 2, 3, 4, 5 and 6 yrs were $82 \%, 65 \%$, $54 \%, 33 \%, 26 \%$ and $23 \%$, respectively. The transplantation-free survival rates after the introduction of i.v. iloprost therapy were $57 \%, 37 \%, 32 \%, 26 \%, 18 \%$ and $15 \%$, respectively. At the end of the observation period, only 8 out of 79 patients $(10 \%)$ had survived without transplantation. The predictors of death, including a low 6-min walk distance and a low mixed-venous 


\begin{tabular}{|c|c|c|c|c|c|}
\hline \multirow[t]{3}{*}{ TABLE 2} & \multicolumn{5}{|c|}{$\begin{array}{l}\text { Risk of an adverse outcome (death or lung transplantation) in relation to risk marker measurements at the time of } \\
\text { the diagnosis }\end{array}$} \\
\hline & & \multicolumn{2}{|c|}{ Simple model } & \multicolumn{2}{|c|}{ Multiple model } \\
\hline & & HR (95\% Cl) & $\mathrm{p}$-value & HR $(95 \% \mathrm{Cl})$ & p-value \\
\hline \multicolumn{2}{|c|}{$\bar{P}$ ra per $1 \mathrm{mmHg}$ increase } & $1.04(0.99-1.1)$ & 0.075 & & \\
\hline \multicolumn{2}{|c|}{$\mathrm{Sv}, \mathrm{O}_{2}$ per $5 \%$ decrease } & $1.14(1.02-1.29)$ & 0.026 & $1.03(1.03-1.53)$ & 0.028 \\
\hline \multicolumn{2}{|c|}{$\bar{P}_{\text {pa }}$ per $5 \mathrm{mmHg}$ increase } & $1.02(0.998-1.19)$ & 0.056 & & \\
\hline \multicolumn{2}{|c|}{ 6MWD per $20 \mathrm{~m}$ decrease } & $1.12(1.05-1.24)$ & 0.001 & $1.12(1.05-1.21)$ & 0.001 \\
\hline \multicolumn{2}{|c|}{ NYHA class } & $1.20(0.61-2.12)$ & 0.589 & & \\
\hline
\end{tabular}

Estimated hazard ratios (HR), 95\% confidence intervals (Cl), and p-values were calculated by simple and stepwise forward Cox regression analyses. HRs refer to the indicated scales in these variables. Pra: mean right atrial pressure; PVR: pulmonary vascular resistance; $\mathrm{Sv}_{\mathrm{V}} \mathrm{O}_{2}$ : mixed venous oxygen saturation; $\bar{P}_{\text {pa: }}$ mean pulmonary artery pressure; 6MWD: 6-min walk distance; NYHA: New York Heart Association.

oxygen saturation at the time of diagnosis, were in accordance with previous studies [16-19].

What are the explanations for these disturbingly high rates of treatment failure? First of all, the 79 patients under study might have represented a "negative selection" from a much larger population of $480 \mathrm{PAH}$ patients, in that they could not be stabilised with inhaled iloprost and conventional therapy. On the other hand, the patients under study were "positively selected" as they had survived from the initial diagnosis to the onset of i.v. iloprost therapy, i.e. a median time of 12 months after the diagnosis of PAH had been made. Both factors created a selection bias in opposite directions and the net effect is unclear.

Beyond any doubt, the patients under study had very severe and aggressive disease as underscored by the haemodynamic data at the time of the initial diagnosis, which revealed a mean PVR of $>1.500 \mathrm{dyn} \cdot \mathrm{s} \cdot \mathrm{cm}^{-5}$, a mean right atrial pressure of

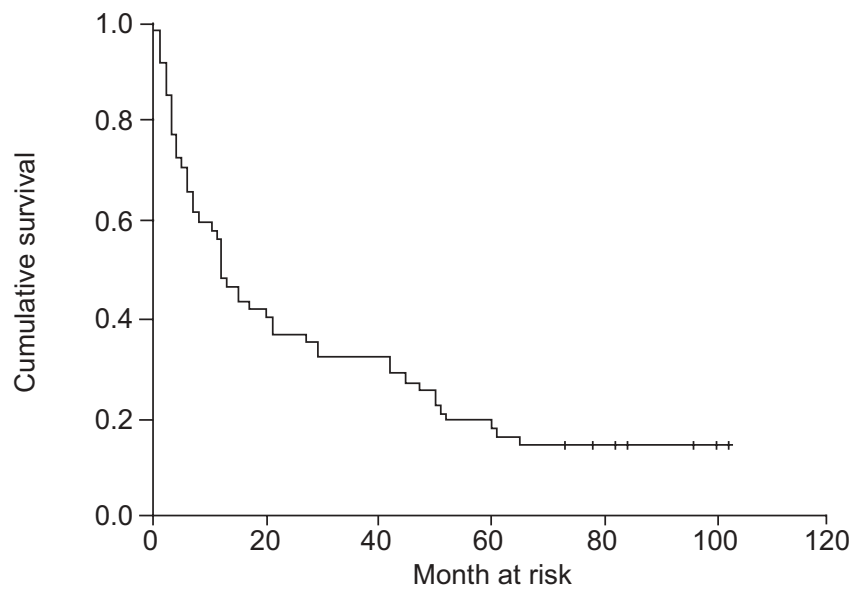

FIGURE 2. Transplantation-free survival from the onset of intravenous iloprost therapy of patients with pulmonary arterial hypertension treated with a sequential approach of inhaled and i.v. iloprost $(n=79)$. Numbers at risk were $n=41, n=27$, $n=24, n=19, n=12$ and $n=6$ after 1, 2, 3, 4, 5 and 6 yrs, respectively. |: censored.
$10 \mathrm{mmHg}$, and a mean mixed-venous oxygen saturation of $54 \%$. At the time when i.v. iloprost was started, the mean PVR had risen to $>1.850 \mathrm{dyn} \cdot \mathrm{s} \cdot \mathrm{cm}^{-5}$, the mean right atrial pressure was now $13 \mathrm{mmHg}$, and the mean mixed venous oxygen saturation had dropped to $47 \%$, showing that the patients had advanced right-heart dysfunction at that time. The introduction of i.v. iloprost therapy resulted in a sustained reduction of the pulmonary vascular resistance $(-19 \%$ from baseline after $2-$ 15 months). This effect was apparently less pronounced than has been reported with i.v. epoprostenol by SITBON et al. [18] (-30\% after 3 months) and MCLAUGHLIN et al. [16] (-39\% after an average treatment time of 17 months). This difference may be partly explained by the fact that the patients in the present study were pre-treated, whereas the patients in the epoprostenol series were treatment-naive. Other factors, however, might also have played a role including the dosing of iloprost as discussed below and the lack of a standardised protocol for follow-up catheterisations, which could have created another bias in that patients responding less well to therapy might have been more likely to undergo repeated right-heart catheterisation.

It is interesting and sobering at the same time to see that the introduction of i.v. iloprost treatment was associated with a haemodynamic benefit as well as a substantial improvement in exercise capacity after 3 months of therapy (as indicated by an improvement of at least one functional class in $38 \%$ of the patients and an average gain in 6-min walking distance by $82 \mathrm{~m})$, but that the overall outcome of these patients was nevertheless poor.

It could be argued that the poor long-term outcome of the patients in the present study might have been related to the fact that i.v. iloprost treatment was not started at the time of the diagnosis but only when patients deteriorated while being treated with inhaled iloprost, and therefore too late. There is no way to prove whether this assumption is right or wrong. However, the overall survival from the time of diagnosis of the patients under study was comparable to a yet unpublished series of patients treated in the UK first-line with i.v. iloprost (P. Corris and co-workers (Cardiothoracic Centre, Freeman 


\begin{tabular}{|c|c|c|c|c|c|}
\hline \multirow[t]{3}{*}{ TABLE 3} & \multicolumn{5}{|c|}{$\begin{array}{l}\text { Risk of an adverse outcome (death or lung transplantation) in relation to risk marker measurements at the onset of } \\
\text { intravenous iloprost therapy }\end{array}$} \\
\hline & & \multicolumn{2}{|c|}{ Simple model } & \multicolumn{2}{|c|}{ Multiple model } \\
\hline & & HR (95\% Cl) & p-value & HR $(95 \% \mathrm{Cl})$ & $\mathrm{p}$-value \\
\hline \multicolumn{2}{|c|}{ Pra per $1 \mathrm{mmHg}$ increase } & $1.05(1.0-1.09)$ & 0.042 & & \\
\hline \multicolumn{2}{|c|}{$\mathrm{Sv}, \mathrm{O}_{2}$ per $5 \%$ decrease } & $1.3(1.13-1.5)$ & $<0.001$ & $1.1(1.01-1.2)$ & 0.003 \\
\hline \multicolumn{2}{|c|}{$\bar{P}$ pa per $5 \mathrm{mmHg}$ increase } & $1.03(0.95-1.1)$ & 0.49 & & \\
\hline \multicolumn{2}{|c|}{ 6MWD per $20 \mathrm{~m}$ decrease ${ }^{\#}$} & $1.0(0.99-1.01)$ & 0.6 & & \\
\hline \multicolumn{2}{|c|}{ NYHA class } & $1.7(1.2-2.8)$ & 0.046 & & \\
\hline
\end{tabular}

Estimated hazard ratios (HR), 95\% confidence intervals (CI), and p-values were calculated by simple and stepwise forward Cox regression analyses. HRs refer to the indicated scales in these variables. $\bar{P}_{\text {ra: }}$ mean right atrial pressure; PVR: pulmonary vascular resistance; $\mathrm{Sv}_{\mathrm{O}} \mathrm{O}_{2}$ : mixed venous oxygen saturation; $\bar{P}_{\text {pa: }}$ mean pulmonary artery pressure; 6MWD: 6-min walk distance; NYHA: New York Heart Association. ${ }^{\#}$ : 6MWD data were available for only 42 patients; ": NYHA data were available for only 73 patients.

Hospital, Newcastle-upon-Tyne, UK), personal communication).

Another possible reason for the limited success with i.v. iloprost therapy might have been underdosing. The optimal dose of i.v. iloprost has never been studied but there is probably the same individual variability as seen with epoprostenol $[16,18,20]$. The average dose of iloprost in the present study $\left(2.6 \mathrm{ng} \cdot \mathrm{kg}^{-1} \cdot \mathrm{min}^{-1}\right.$ after a median treatment time of 6 months) was in the same range as the iloprost dose used by HigenBOTTAM et al. [13] in an earlier pilot study $\left(2.1 \mathrm{ng} \cdot \mathrm{kg}^{-1} \cdot \mathrm{min}^{-1}\right.$ after a median treatment time of 7 weeks) but lower than the iloprost dose used in the above-mentioned unpublished study from the UK $\left(3.3 \mathrm{ng} \cdot \mathrm{kg}^{-1} \cdot \mathrm{min}^{-1}\right.$ after 3 months and $4.7 \mathrm{ng} \cdot \mathrm{kg}^{-1} \cdot \mathrm{min}^{-1}$ after $1 \mathrm{yr}$, respectively; P. Corris and co-workers, personal communication). We cannot exclude the possibility that more aggressive dosing might have resulted in better treatment results.
Do the present data suggest that i.v. iloprost might be less efficacious than i.v. epoprostenol? This is certainly the key question. i.v. epoprostenol remains the only therapy for which a survival benefit has been shown in a randomised controlled clinical trial [1]. That study, however, was an unblinded shortterm study of 12-week duration. Long-term survival with i.v. epoprostenol has never been assessed in a randomised controlled fashion and most of the evidence comes from two large series published several years ago $[16,18]$. The overall survival rates of the patients in the present study from the time of diagnosis (censoring patients at the time of transplantation) were similar to those reported with i.v. epoprostenol, but the survival rates on i.v. therapy were considerable lower. All in all, there are too many differences between the present study and the epoprostenol series to allow a fair comparison of the two treatments.

Although it is generally accepted that i.v. epoprostenol therapy has a beneficial effect on survival in PAH patients, improved

Haemodynamic variables at the time of the diagnosis of pulmonary arterial hypertension, immediately before initiation of intravenous iloprost treatment, at the end of the initial up-titration period, and during follow-up $(n=37)$

\begin{tabular}{|c|c|c|c|c|}
\hline & Baseline & Before start of i.v. iloprost & After dose up-titration & Follow-up \\
\hline When variables measured & $\begin{array}{l}\text { First right-heart catheter } \\
\text { at diagnosis of PAH }\end{array}$ & $\begin{array}{l}\text { Immediately before the } \\
\text { introduction of } i . v \text {. iloprost }{ }^{\#}\end{array}$ & $\begin{array}{l}\text { Initial haemodynamic } \\
\text { response to iloprost }\end{array}$ & $\begin{array}{c}\text { Median } 6 \text { (range } 2-15 \text { ) months) } \\
\text { on i.v. iloprost therapy }\end{array}$ \\
\hline Pra $\mathrm{mmHg}$ & $10 \pm 6$ & $13 \pm 6$ & $10 \pm 5$ & $11 \pm 5$ \\
\hline $\bar{P}_{\text {pa }} \mathrm{mmHg}$ & $59 \pm 13$ & $63 \pm 15$ & $60 \pm 15$ & $58 \pm 14$ \\
\hline Cardiac interval $\mathrm{L} \cdot \mathrm{min}^{-1} \cdot \mathrm{m}^{-2}$ & $1.8 \pm 0.6$ & $1.5 \pm 0.3$ & $1.9 \pm 0.5^{\star}$ & $1.6 \pm 0.5$ \\
\hline PVR dyn $\cdot \mathbf{s} \cdot \mathbf{c m}^{-5}$ & $1,563 \pm 602$ & $1,965 \pm 871$ & $1,474 \pm 606^{*}$ & $1,594 \pm 651^{*}$ \\
\hline $\mathrm{Sv}, \mathrm{O}_{2} \%$ & $53 \pm 11$ & $46 \pm 10$ & $57 \pm 10^{*}$ & $53 \pm 10^{*}$ \\
\hline
\end{tabular}

Data are presented as mean \pm SD. Pra: right atrial pressure; $\bar{P}$ pa: mean pulmonary arterial pressure; Ppcw: pulmonary capillary wedge pressure; CO: cardiac output; PVR pulmonary vascular resistance; $\mathrm{Sv}, \mathrm{O}_{2}$ : mixed venous oxygen saturation. ${ }^{*}$ : the median interval between the first and the second right heart catheterisation was 12 months. *: $p<0.05$ versus immediately before the introduction of $i . v$. iloprost. 
long-term outcome has never been formally proved with any $\mathrm{PAH}$ therapy, including i.v. epoprostenol. In fact, looking at the long-term survival with any i.v. prostanoid may raise concerns as to whether these drugs truly slow or halt disease progression since the effect on survival seems most prominent in the first year of treatment, but not thereafter. Given the invasiveness, risks and costs associated with i.v. prostacyclin therapy, more long-term data are certainly needed, but there are several ethical and practical obstacles to conducting randomised controlled long-term trials with i.v. prostanoids. Just looking at the long-term results with i.v. prostanoid therapy indicates that the current options for treating patients with the most advanced forms of PAH remain limited. The best therapeutic approach to patients with the most severe forms of pulmonary hypertension remains unknown, although emerging data suggest that the survival of these patients may improve with combination therapy [21, 22]. However, it is likely that the best chances to improve the outcome of PAH patients lie in early diagnosis and prompt targeted intervention [23].

The present study has some limitations, especially the retrospective design, the heterogeneous patient population, the sequential therapeutic approach, the lack of a control group and the abundance of missing data, which make interpretation of the data difficult. The present data should be viewed merely as descriptive and as such they are important as they represent the most valuable source of information on the long-term outcome with this treatment currently available.

In conclusion the use of i.v. iloprost in patients deteriorating while being treated with inhaled iloprost improves haemodynamics but has an unclear effect on the long-term survival of these patients.

\section{STATEMENT OF INTEREST}

Statements of Interest for M.M. Hoeper, H.J. Seyfarth, M. Halank, H.A. Ghofrani, J. Winkler, K.M. Olsson, C. Opitz and R. Ewert can be found at www.erj.ersjournals.com/misc/statement.dtl

\section{REFERENCES}

1 Barst RJ, Rubin LJ, Long WA, et al. A comparison of continuous intravenous epoprostenol (prostacyclin) with conventional therapy for primary pulmonary hypertension. The Primary Pulmonary Hypertension Study Group. N Engl J Med 1996; 334: 296-302.

2 Badesch DB, Tapson VF, McGoon MD, et al. Continuous intravenous epoprostenol for pulmonary hypertension due to the scleroderma spectrum of disease. A randomized, controlled trial. Ann Intern Med 2000; 132: 425-434.

3 Rubin LJ. Primary pulmonary hypertension. N Engl J Med 1997; 336: 111-117.

4 Dupuis J, Hoeper MM. Endothelin receptor antagonists in pulmonary arterial hypertension. Eur Respir J 2008; 31: 407-414.

5 Wilkins MR, Wharton J, Grimminger F, et al. Phosphodiesterase inhibitors for the treatment of pulmonary hypertension. Eur Respir J 2008; 32: 198-209.
6 Olschewski H, Gomberg-Maitland M. Prostacyclin therapies for the treatment of pulmonary arterial hypertension. Eur Respir J 2008; 31: 801-901.

7 Galie N, Torbicki A, Barst R, et al. Guidelines on diagnosis and treatment of pulmonary arterial hypertension. The Task Force on Diagnosis and Treatment of Pulmonary Arterial Hypertension of the European Society of Cardiology. Eur Heart J 2004; 25: 22432278.

8 Badesch DB, Abman SH, Ahearn GS, et al. Medical therapy for pulmonary arterial hypertension: ACCP evidence-based clinical practice guidelines. Chest 2004; 126: Suppl. 1, 35S-62S.

9 Goldsmith DR, Wagstaff AJ. Inhaled iloprost: in primary pulmonary hypertension. Drugs 2004; 64: 763-773.

10 Olschewski H, Rohde B, Behr J, et al. Pharmacodynamics and pharmacokinetics of inhaled iloprost, aerosolized by three different devices, in severe pulmonary hypertension. Chest 2003; 124: 1294-1304.

11 Hoeper MM, Spiekerkoetter E, Westerkamp V, et al. Intravenous iloprost for treatment failure of aerosolised iloprost in pulmonary arterial hypertension. Eur Respir J 2002; 20: 339-343.

12 Ewert R, Opitz CF, Wensel R, et al. Continuous intravenous iloprost to revert treatment failure of first-line inhaled iloprost therapy in patients with idiopathic pulmonary arterial hypertension. Clin Res Cardiol 2007; 96: 211-217.

13 Higenbottam TW, Butt AY, Dinh-Xaun AT, et al. Treatment of pulmonary hypertension with the continuous infusion of a prostacyclin analogue, iloprost. Heart 1998; 79: 175-179.

14 Higenbottam T, Butt AY, McMahon A, et al. Long-term intravenous prostaglandin (epoprostenol or iloprost) for treatment of severe pulmonary hypertension. Heart 1998; 80: 151-155.

15 D'Alonzo GE, Barst RJ, Ayres SM, et al. Survival in patients with primary pulmonary hypertension. Results from a national prospective registry. Ann Intern Med 1991; 115: 343-349.

16 McLaughlin VV, Shillington A, Rich S. Survival in primary pulmonary hypertension: the impact of epoprostenol therapy. Circulation 2002; 106: 1477-1482.

17 McLaughlin VV, Sitbon O, Badesch DB, et al. Survival with firstline bosentan in patients with primary pulmonary hypertension. Eur Respir J 2005; 25: 244-249.

18 Sitbon $\mathrm{O}$, Humbert $\mathrm{M}$, Nunes $\mathrm{H}$, et al. Long-term intravenous epoprostenol infusion in primary pulmonary hypertension: prognostic factors and survival. J Am Coll Cardiol 2002; 40: 780-788.

19 Provencher S, Sitbon O, Humbert M, et al. Long-term outcome with first-line bosentan therapy in idiopathic pulmonary arterial hypertension. Eur Heart J 2006; 27: 589-595.

20 Rich S, McLaughlin VV. The effects of chronic prostacyclin therapy on cardiac output and symptoms in primary pulmonary hypertension. J Am Coll Cardiol 1999; 34: 1184-1187.

21 Hoeper MM, Markevych I, Spiekerkoetter E, et al. Goal-oriented treatment and combination therapy for pulmonary arterial hypertension. Eur Respir J 2005; 26: 858-863.

22 Simonneau G, Rubin LJ, Galie N, et al. Addition of sildenafil to long-term intravenous epoprostenol therapy in patients with pulmonary arterial hypertension: a randomized trial. Ann Intern Med 2008; 149: 521-530

23 Galie N, Rubin L, Hoeper M, et al. Treatment of patients with mildly symptomatic pulmonary arterial hypertension with bosentan (EARLY study): a double-blind, randomised controlled trial. Lancet 2008; 371: 2093-2100. 